\title{
Absence behaviour as traffic crash predictor in bus drivers
}

\author{
A. E. af Wåhlberg* (1) \\ and \\ L. Dorn (2) \\ 1. Department of Psychology \\ Uppsala University \\ P. O. Box 1225 \\ 75142 Uppsala \\ Sweden \\ e-mail: anders.af_wahlberg@psyk.uu.se \\ Homepage: http://www.psyk.uu.se/hemsidor/busdriver \\ Tel: +46-18-471 25 90, +46-18-339095 \\ 2. Department of Human Factors, \\ Cranfield University, Cranfield, Bedfordshire, MK43 0AL \\ United Kingdom \\ * Corresponding author
}

\begin{abstract}
Problem: Various indicators of health have been shown to be associated with traffic crash involvement. As general health is also related to absence from work, the latter variable may be more strongly related to crashes, especially for professional drivers.

Method: Bus driver absence from work by was analyzed in association with their crash records. Two British and one Swedish sample were used.

Results: One of the British samples yielded fair correlations between crash record and absence, while for the other the effect was restricted to the first three months of driving. The Swedish data had effects in the expected direction but these were not significant.
\end{abstract}


Discussion: The use of an indirect, overall measurement of health, may be a viable method for predicting the traffic crash involvement for professional drivers although replications are needed in larger samples and other populations.

Impact on industry: The use of absence records for the identification of at risk drivers would seem to be a simple and useful method for companies with major fleets, and it also show the importance of promoting employee health and well being at work as a potential method of reducing the cost not only of absenteeism but also crashes in company vehicles. 


\section{Introduction}

Within traffic safety research, the attempts to predict individual differences in crash liability have received a fair amount of attention (see reviews for example by Lester, 1991; Arthur, Barrett \& Alexander, 1991; Clarke \& Robertson, 2005). As most of the predictors used have been very specific, in that they probably are causally related to only a subset of crashes, effect sizes have generally been small. One set of predictors that have received little attention is health-related ones. Among those found to be associated with traffic crash record are obesity (Yamamoto, Akashiba, Kosaka, Ito \& Horie, 2000), sleep apnoea (e.g., Findley, Unverzagt \& Suratt, 1988; Young, Blustein, Finn \& Palta, 1997; Barbé et al, 1998), and possibly exercise (see the review by Taylor \& Dorn, 2006; Taylor \& Dorn, 2008). For medical condition and treatment variables, correlations are in general very small, but reliable effects seem to have been found for diabetes (Cox et al., 2003), epilepsy (Lings, 2001) and various medications (Leveille, Buchner, Koepsell, McCloskey, Wolf \& Wagner, 1994; Hemmelgarn, Suissa, Huang, Boivin \& Pinard, 1997; and possibly Lagarde, Chastang, Lafont, Coeuret-Pellicer \& Chiron, 2005, although it was uncertain whether the effects were due to health problems as such or the medications to treat the ailments).

The interesting aspect of the previous research in the use of healthrelated variables as predictors of crash involvement is that they should all be associated with absence from work. As yet, research to show a link between absenteeism and traffic crash involvement for professional drivers (who have a higher exposure to crash risk) has not been demonstrated previously.. Furthermore, if the wide ranging health conditions previously studied yield an effect on crashes as well as 
absence, then the sum should be much larger than these variables individually. It is therefore possible that absence from work may be a good predictor of traffic crash involvement.

Bearing in mind that absence from work is in itself an unwanted behaviour for companies, a link between absence and at-work crashes for professional drivers could be important information for managing at-work road risk.

Over fifty years ago, similar research on workplace injuries and absenteeism has been reported for industrial workers (Farmer \& Chambers, 1926; 1929), but can be suspected to be somewhat inflated, due to absences being caused by the injuries sustained (see Verrier \& Chevalier, 2007). However, in heavy vehicle ( $>10$ tons) driver populations, such an effect is unlikely, due to the protection offered to the driver by the weight and sturdiness of such vehicles. This is especially true for bus drivers in city areas, where speeds are low; injuries to drivers are extremely rare (af Wåhlberg, 2002). Also, bus drivers have high levels of work-related health problems (for reviews, see Long \& Perry, 1985; Kompier \& Di Martino, 1995; Tse, Flin \& Mearns, 2006), making them a good population to study the proposed effect.. The present study therefore set out to investigate whether absence from work is associated with bus crashes for at work bus drivers. Of empirical interest is the notion of broad variables being better crash predictors than specific ones but this is beyond the scope of the present study.

\section{Method}

Samples 
Three sets of bus driver data were used for the present study; two from a major UK bus company, and one from a small bus company in Sweden; Gamla Uppsalabuss (GUB). Data on descriptive variables for these samples are shown in Tables 1 and 2.

In the UK, the operators in sample 1 were newly hired and had taken part in a simulator-based study which required their crash and absence data to be collected for a period of 12 months after they began operational driving (see Dorn, Stephen \& af Wåhlberg, in press). Therefore, these data had differing starting points and were not for the same time period for individual drivers.. Traffic crash data were available for every three months of operational driving for each of the drivers.

Sample 2 consisted of bus drivers from two different locations within the UK; London and the North West of England, including North Wales and Manchester. Some operational and situational differences can be noted between these two groups; the London area has heavier traffic, more modern vehicles (and fewer different types), more CCTV surveillance on the vehicle, no fares collection by the drivers, and more supervision from managers. Data for these groups were added together across both samples due to small Ns. Both UK samples consisted of full time drivers only.

For the Swedish sample, all drivers who had worked on full time schedules from 1999 to 2005 (as identified by their employee numbers) were included in the study, apart from those who worked less than ten hours in any year (about two standard deviations from the mean for each year). Gamla Uppsalabuss (GUB) run all intra-city bus routes of Uppsala, the fourth largest town of Sweden, and has about 180 buses and 350 drivers at any time. A substantial number of the drivers work part time. Descriptive data for one year for the Swedish sample are shown in Table 2. 
Tables 1-2 about here

Data

For the UK samples, absence (number of days off work) and crash data were available from the employer for one year for sample 1 and 6 months for sample 2. All incidents resulting in damage and/or injury involving the bus are reported by the drivers, and culpability for these (including falls in the bus) are determined by the driver's manager and an insurance team, taking in such information as the driver's report, photographs, witness reports etc. In the present study, two crash variables were used (All crashes and Culpable crashes) to test the hypothesis that absenteeism is associated with crashes. Theoretically, only crashes that the drivers have had some part in causing should be used as a criterion, as non-culpable incidents cannot be predicted (af Wåhlberg, 2008a; 2008b; af Wåhlberg \& Dorn, 2007; 2009).

However, as it has been shown that the criterion used by this bus company to determine responsibility is somewhat too lenient (af Wåhlberg \& Dorn, 2007). This means that the 'culpable only' variable will exclude a number of incidents that should rightly have been included, while the 'All' variable includes about 30 percent of incidents that are not the bus driver's fault and should therefore be excluded. As it was not possible to determine which crashes should have been excluded, both variables were included as the optimal dependent variable would be somewhere in between these variables.

For the Swedish drivers, hours actually worked and crash data were available for the period 1999-2005. Regarding culpability for crashes, the criterion 
used for categorization had been shown to be approximately correct, classifying about 70 percent of crashes as at least partly the fault of the bus driver (af Wåhlberg \& Dorn, 2007). Therefore, only one incident variable (including injuries and hitting animals) was used; culpable crashes. Further descriptions of the bus company and their incident data can be found in af Wåhlberg (2002).

\section{Statistical methods}

The main aim of the study was to estimate the strength of the association between absence and traffic crashes. This can be expressed with many statistical methods, but Pearson correlation was chosen because it can be directly converted into percent explained variance, which is closely related to how well drivers can be classified into correct groups for crash involvement. The crash data used was not normally distributed, but this restricted variance only has the effect of limiting the size of the correlations (Glass \& Hopkins, 1996). However, this effect is small; even when crash data with very restricted variance is used, the results follow a pattern that does not indicate that the correlations shrink faster than the mean of the samples used (af Wåhlberg \& Dorn, 2009). Another indication of the robustness of the Pearson correlation against violations of its assumptions is that log transformation against skewness has no impact (Avolio, Kroeck \& Panek, 1985). Also, as shown by Gebers (1997), what statistical method is used has little impact upon the final result, in terms of explanatory power.

As a complimentary analysis, independent t-tests were used, to bring out possible non-linear effects, where it was possible to dichotomize data in a meaningful 
way. ANOVA-type tests could not be used, as the crashes per hour variable was continuous.

Analyses

The analysis performed involved correlations being run between number of crashes for a specified time period and number of absence days for the same time period. All drivers were all on full-time schedules, and therefore, in principle, equally exposed to risk of crash involvement, although there could exist differences in crash risk between different routes or schedules. However, such differences have been shown to be very small (Häkkinen, 1958).

Conversely, full time drivers who are absent from work and therefore operational driving have a lower risk exposure directly related to their amount of absence. Crashes per time period are therefore not a truly equivalent outcome measure for these drivers. Therefore, the number of crashes per day or hour actually worked was computed to control for the difference in risk exposure due to absenteeism. For the UK drivers, hours worked were estimated by subtracting their absences from their expected number of working days and the remainder was used as the denominator for the number of crashes per day ratio calculation. For the Swedish sample, only hours actually worked were available. Although it was not known exactly how many hours they were expected to work, the normal Swedish working year is around 1800 hours, which was used as the expected number. The expectation was that absence would correlate somewhat more strongly with this variable, as compared with the crashes per year variable, because the latter would not be held constant for exposure. 


\section{Results}

UK sample 1

First, the number crashes for the whole time period and the number of crashes per actual working day ${ }^{1}$ were correlated with absence, as shown in Table 3. As data was available for four different, cumulative time periods from the drivers' start of employment and correlations were run for all of these time periods. It can be noted that only for the shortest time period was there an association of any size between the variables of interest.

One extreme outlier for absenteeism was deleted from one calculation, and several more could have been excluded, if the normal statistical criterion of two standard deviations from the mean had been used. However, analyses determined that these deviating cases did not have any discernible effect on the results.

Tables 3-4 about here

UK sample 2

The analysis was similar to that of sample 1, although restricted to one time period only. The results are shown in Table 4. As expected, the correlations for crashes per day were stronger than the ones for crashes per year, as was the case for all but one comparison in sample 1 . When the same analyses were run for the subgroups of this sample (different areas in the UK) results were very similar.

\section{Swedish sample}

\footnotetext{
${ }^{1}$ Accidents per day $=\frac{\text { Noofaccidents }}{\text { Expecteddays }- \text { absence }}$
} 
First, the correlations between hours worked in different years were computed (see Table 5). From these results, it could be gleaned that there was a strong tendency for (full-time) drivers to work a certain number of hours consistently over time. This can be interpreted as evidence that absent prone drivers tend to be off work sick over extended time periods, i.e. in other words, absenteeism is a fairly stable disposition within individual drivers (see further the discussion).

The correlations between absence and number of crashes and crashes per hour worked for 1999-2005 was -.050 and .089, respectively ( $\mathrm{N}=150, \mathrm{p}>.05)$. Thereafter, absence was dichotomized into the groups who worked more and less than 10800 hours in the time period studied. The not-absent group had 0.111 crashes per 1000 hours, while the absent group had 0.145 . Whilst on the face of it, this appears to be a substantial difference between the groups, the groupswere not significantly different from each other at $\mathrm{p}<.05$ (independent $\mathrm{t}$-test, $\mathrm{t}=1.33$ ). However, close inspection of the data revealed that there were a number of drivers who had worked very few hours, and in conjunction with the very low risk of crash for this company (see Table 2), it could be suspected that these results were indicative of a real effect that was suppressed due to the number of cases $=$ of drivers driving very little and having had no crashes. For this reason, the drivers with no crashes were excluded, and the correlations re-run. This method yielded associations of .037 and $.279(\mathrm{~N}=95$, $\mathrm{p}<.01)$ with absence.

Table 5 about here

\section{Discussion}


The present study would seem to lend some tentative support to the hypothesis of absence behaviour as a predictor of traffic crashes amongst professional drivers, but more evidence is required. However, as the crash variable has low statistical power, further research would require larger samples.

The first UK sample results were hard to interpret, as the effect at three months was apparently carried by those who thereafter left the company (no correlation was present at three months if the sample was restricted to those who remained with the company). Staplin and Gish (2005) reported that drivers who change jobs frequently have higher crash risks, and in the light of their research, the present findings would seem to be reasonable. It could be argued that the UK sample confirmed the hypothesis in all instances but one; the correlation between absenteeism and crashes increased when these were calculated by working day instead of by year, as similarly (but more strongly) was the case in sample 2 from the UK.

The present data showed that it was not very likely that drivers had been injured and/or shocked in crashes and thereafter been on sickness leave. Buses are heavy and sturdy vehicles, which protect their occupants well. Also, for the Swedish data, almost all driving takes place in 30 and $50 \mathrm{~km} / \mathrm{h}$ speed limit zones, and injuries constitutes less than ten percent of incidents (af Wåhlberg, 2002), and the injuries sustained are usually to passengers. Therefore, it seems unlikely that absence could be caused by crashes in bus driver populations.

It is, in principle, possible that some of the UK results were due to a third variable; unequal risk and stress exposure between routes. However, drivers are not allocated systematically to the same routes and all drivers have a similar chance of being exposed to the routes with higher risk. This is potential effect is not possible for the Swedish drivers, as they all drove the majority of routes. 
The association between absence and traffic crashes, if reliably

confirmed in future research, could be used by fleet-based companies to improve safety at work. Drivers who are often absent are not only an organizational cost including driver substitution and turnover, but also as safety hazards. There are thus many reasons for targeting such drivers with remedial action, especially to promote a healthier lifestyle and general good health.

Within traffic research, it has sometimes been reported that mileage is curvilinearly related to crashes (e.g., Maycock, 1996), i.e. when exposure is very high, crashes hardly increase at all. This has usually been interpreted as an experience effect, with increased driving causing higher skill and crash avoidance. However, this effect may just as well be due to the opposite mechanism, with less proficient drivers driving less, as indicated in the present study. It could therefore be the case that exposure is actually fairly linearly associated with crashes, and the apparent curvilinearity is caused to some degree by the opposing effect of high-absence drivers having more crashes and driving less. This explanation is of course more viable for professional samples, but it is possible that such a mechanism is at work amongst private driver populations too. After all, a proportion of our driving is commuting to and from work, and people who are sick probably abstain somewhat from driving privately as well. To test this proposition, studies are needed on the driving habits of people in relation to their sickness and absences from work. The reported curvilinearity of crashes versus mileage might also be due to artifacts created by the self-report method usually used in such studies (Staplin, Gish \& Joyce, 2008).

The phenomenon of absenteeism from work is a lively research area in its own right, and would seem to be fairly well developed (for a review, see Johns, 
2003). In this research, it would seem that it has been implicitly assumed that it is the crashes that cause long-term absences (e.g., Ose, 2005). The present hypothesis and results, however, would seem to lend a new perspective to this endeavor. Future research might focus on performing a meta-analysis to sort studies into those that have used specific and general variables (the latter subsuming the former), may find that the associations are stronger for the general variables.

Acknowledgement

The data used in this paper had been generously made available by a major UK bus company and Gamla Uppsalabuss.

\section{References}

Arthur, W., Jr., Barrett, G. V., \& Alexander, R. A. (1991). Prediction of vehicular accident involvement: A meta-analysis. Human Performance, 4, 89-105.

Avolio, B. J., Kroeck, K. G., \& Panek, P. E. (1985). Individual differences in information-processing ability as a predictor of motor vehicle accidents. Human Factors, 27, 577-589.

Barbe, F., Pericas, J., Munoz, A., Findley, L., Anto, J. M., Agusti, A. G., de Lluc Joan, M. (1998). Automobile accidents in patients with sleep apnoea syndrome. American Journal of Respiratory Critical Care Medicine, 158, 18-22. 
Clarke, S., \& Robertson, I. T. (2005). A meta-analytic review of the Big Five personality factors and accident involvement in occupational and non-occupational settings. Journal of Occupational and Organizational Psychology, 78, 355-376.

Cox, D. J., Penberthy, J. K., Zrebiec, J., Weinger, K., Aikens, J. E., Frier, B., Stetson, B., DeGroot, M., Trief, P., Schaechinger, H., Hermanns, N., Gonder-Frederick, L., \& Clarke, W. (2003). Diabetes and driving mishaps: Frequency and correlations from a multinational survey. Diabetes Care, 26, 2329-2334.

Dorn, L., Garwood, L., \& af Wåhlberg, A. E. (in press). Development of a psychometric measure of bus driver behaviour. Ergonomics,

Farmer, E., \& Chambers, E. G. (1926). A psychological study of individual differences in accident rates. Industrial Health Research Board Report No 38.

Farmer, E., \& Chambers, E. G. (1929). A Study of Personal Qualities in Accident Proneness and Proficiency. Industrial Health Research Board Report No 55.

Findley, L., Unverzagt, M. E., \& Suratt, P. M. (1988). Automobile accidents involving patients with obstructive sleep apnoea. American Review of Respiration Disorder, 138, 337-340.

Gebers, M. A. (1997). Exploratory Multivariable Analyses of California Driver Record Accident Rates. California Department of Motor Vehicles. 
Glass, G. V., \& Hopkins, K. D. (1996). Statistical Methods in Education and Psychology. Boston: Allyn and Bacon. 3rd edition.

Hemmelgarn, B., Suissa, S., Huang, A., Boivin, J. F., \& Pinard, G. (1997).

Benzodiazepine use and the risk of motor vehicle crash in the elderly. JAMA, 278, 27-

31.

Häkkinen, S. (1958). Traffic accidents and driver characteristics. Doctoral thesis, Finland's Institute of Technology.

Johns, G. (2003). How methodological diversity has improved our understanding of absenteeism from work. Human Resource Management Review, 13, 157-184.

Kompier, M. A., \& Di Martino, V. (1995). Review of bus drivers' occupational stress and stress prevention. Stress Medicine, 11, 253-262.

Lagarde, E., Chastang, J.-F., Lafont, S., Coeuret-Pellicer, M., \& Chiron, M. (2005). Pain and pain treatment were associated with traffic accident involvement in a cohort of middle-aged workers. Journal of Clinical Epidemiology, 58, 524-531.

Lester, J. (1991). Individual differences in accident liability: review of the literature. TRRL Research Report 306. Crowthorne: Transport and Road Research Laboratory. 
Leveille, S. G., Buchner, D. M., Koepsell, T. D., McCloskey, L. W., Wolf, M. E. \& Wagner, E. H. (1994) Psychoactive medications and injurious motor vehicle collisions involving older drivers. Epidemiology, 5, 591-598.

Lings, S. (2001). Increased driving accident frequency in Danish patients with epilepsy. Neurology, 57, 435-439.

Long, L., \& Perry, J. (1985). Economic and occupational causes of transit operator absenteeism: A review of research. Transport Reviews, 5, 247-267.

Maycock, G. (1996). Sleepiness and driving: the experience of UK car drivers. Journal of Sleep Research, 5, 229-237.

Ose, S. O. (2005). Working conditions, compensation and absenteeism. Journal of Health Economics, 24, 161-188.

Rentsch, J. R., \& Steel, R. P. (1998). Testing the durability of job characteristics as predictors of absenteeism over a six-year period. Personnel Psychology, 51, 165-190.

Staplin, L., \& Gish, K. W. (2005). Job change rate as a crash predictor for interstate truck drivers. Accident Analysis and Prevention, 37, 1035-1039.

Staplin, L., Gish, K. W., \& Joyce, J. (2008). 'Low mileage bias' and related policy implications-A cautionary note. Accident Analysis and Prevention, 40, 1249-1252. 
Taylor, A. H., \& Dorn, L. (2006). Stress, fatigue, health, and risk of road traffic accidents among professional drivers: The contribution of physical inactivity. Annual Review of Public Health, 27, 371-391

Taylor, A. H., \& Dorn, L. (2008). Prospective relationships between physical activity, 'need for recovery', and driver accidents and absenteeism. In L. Dorn (Ed.) Driver Behaviour and Training, Volume III, pp. 167-173. Aldershot: Ashgate. Third International Conference on Driver Behaviour and Training. Dublin 12-13 November, 2007.

Tse, J. L., Flin, R., \& Mearns, K. (2006). Bus driver well-being review: 50 years of research. Transportation Research Part F, 9, 89-114.

Verrier, A., \& Chevalier, A. (2007). Home and leisure injuries among the French electricity and gas company active employees: Circumstances and short-term consequences. Accident Analysis and Prevention, , -.

af Wåhlberg, A. E. (2002). Characteristics of low speed accidents with buses in public transport. Accident Analysis and Prevention, 34, 637-647.

af Wåhlberg, A. E. (2008a). Driver celeration behavior and accidents - an analysis. Theoretical Issues in Ergonomics Science, 9, 383-403.

af Wåhlberg, A. E. (2008b). The relation of non-culpable traffic incidents to bus drivers' celeration behavior. Journal of Safety Research, 39, 41-46. 
af Wåhlberg, A. E., \& Dorn, L. (2007). Culpable versus non-culpable traffic accidents; what is wrong with this picture? Journal of Safety Research, 38, 453-459.

af Wåhlberg, A. E., \& Dorn, L. (2009). Bus driver accident record; the return of accident proneness. Theoretical Issues in Ergonomics Science, 10, 77-91.

Yamamoto, H., Akashiba, T., Kosaka, N., Ito, D., \& Horie, T. (2000). Long-term effects nasal continous positive airway pressure on daytime sleepiness, mood and traffic accidents in patients with obstructive sleep apnoea. Respiratory Medicine, 94, $87-90$

Young, T., Blustein, J., Finn, L., \& Palta, M. (1997). Sleep-disordered breathing and motor vehicle accidents in a population-based sample of employed adults. Sleep, 20, 608-613. 
Table 1

The descriptive data (means and standard deviations) for the UK samples; percent men, age, years since car or PCV licensing, number of months with the company, number of crashes (all) and days of absence in the period given in the last column.

\begin{tabular}{|c|c|c|c|c|c|c|c|c|}
\hline Sample & $\mathrm{N}$ & Sex & Age & License & Experience & $\begin{array}{l}\text { All } \\
\text { crashes }\end{array}$ & Absence & Time period \\
\hline $\begin{array}{l}\text { UK } \\
\text { sample } 1\end{array}$ & 176 & $86.7 \%$ & $37.6 / 10.0$ & car? & - & $0.59 / 0.83$ & $1.03 / 2.43$ & $\begin{array}{l}3 \text { months (after } \\
\text { training) }\end{array}$ \\
\hline $\begin{array}{l}\text { UK } \\
\text { sample } 2\end{array}$ & 153 & $92.2 \%$ & $47.4 / 10.2$ & $\begin{array}{l}13.4 / 12.1 \\
(\mathrm{PCV})\end{array}$ & $100.3 / 105.7$ & $2.99 / 2.63$ & $1.84 / 0.89$ & 12 months \\
\hline
\end{tabular}




\section{Table 2}

The descriptive data (means and standard deviations) for the Swedish sample. Percent men, age, number of years with the company in 2003, and number of culpable crashes. Drivers with less than ten hours worked per year excluded.

\begin{tabular}{llllll}
\hline $\mathrm{N}$ & Sex & Age & Experience & Culpable crashes 1999-2005 & Hours worked 1999-2005 \\
\hline 150 & $88 \%$ & $48.6 / 8.3$ & $16.3 / 9.2$ & $1.32 / 1.52$ & $10981 / 1902$ \\
\hline
\end{tabular}


Table 3

The correlations between absence from work and number of traffic crashes (per year and per days worked in the same period) during the same time period, for the UK sample 1 bus drivers.

\begin{tabular}{lcllll}
\hline \multicolumn{5}{c}{ All crashes } & \multicolumn{3}{c}{ Culpable crashes } \\
\hline Time period & $\mathrm{N}$ & Per year & Per day worked & Per year & Per day worked \\
Three months & 176 & $.255^{* * *}$ & $.267^{* * *}$ & $.200 * *$ & $.207 * *$ \\
Six months & 167 & .089 & .100 & .064 & .074 \\
Nine months & 137 & .093 & .135 & .035 & .065 \\
Twelve months & $81 \#$ & .038 & .060 & -.027 & -.012 \\
\hline
\end{tabular}

** $\mathrm{p}<.01, * * * \mathrm{p}<.001$

\# One outlier deleted from absence variable. 
Table 4

The correlations between absence from work and number of traffic crashes (per year and per days

worked in the same period) during the same time period 12 months, for the bus drivers in UK sample 2.

$\mathrm{N}=153$.

Variable All crashes Culpable crashes

Per year Per day worked Per year Per day worked

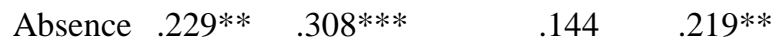

** $\mathrm{p}<.01, * * * \mathrm{p}<.001$ 
Table 5

The correlations between hours worked in different years for full-time workers in the Swedish sample.

Drivers with less than ten hours worked per year excluded. $\mathrm{N}=150$.

\begin{tabular}{|c|c|c|c|c|c|c|}
\hline Year & 2000 & 2001 & 2002 & 2003 & 2004 & 2005 \\
\hline 1999 & $.205^{*}$ & $.216^{* *}$ & $.185^{*}$ & $.207 *$ & $.187 *$ & .140 \\
\hline 2000 & & $.734 * * *$ & $.678 * * *$ & $.662 * * *$ & $.602 * * *$ & $.478 * * *$ \\
\hline 2001 & & & $.743 * * *$ & $.654 * * *$ & $.612 * * *$ & $.437 * * *$ \\
\hline 2002 & & & & $.733 * * *$ & $.612 * * *$ & $.404 * * *$ \\
\hline 2003 & & & & & $.714 * * *$ & $.482 * * *$ \\
\hline 2004 & & & & & & $.606 * * *$ \\
\hline
\end{tabular}

